\title{
Synthesis, Characterization and Studies of PANI-MMT Nanocompoisites
}

\author{
Sridhar Pande ${ }^{1}$, Swaruparani $\mathbf{H}^{1}$, Mahesh D. Bedre ${ }^{1}$, Ravis hankar Bhat ${ }^{1}$, Raghunadan Deshpande ${ }^{2}$, \\ A. Venkataraman ${ }^{1, *}$ \\ ${ }^{1}$ Department of Materials Science, Gulbarga University, Gulbarga-585106, Karnataka, India \\ ${ }^{2}$ H.K.E.'s Matoshree Taradevi Rampure Institute of Pharmaceutical Sciences, Sedam Road, Gulbarga, 585105, Karnataka, India
}

\begin{abstract}
In this work synthesis \& characterization of composite materials based on montmorillonite (MMT) clay and intrinsically conducting polyaniline (PANI) is studied. The MMT type of clay used is locally available in the region which was used after chemical activation. The main thrust of this work was to know the possibility of usage of locally available clay to synthesise novel nanocomposites. Synthesises of PANI and processing and treatment of this clay was carried out in the lab by the authors. PANI was successfully incorporated into MMT to form PANI-MMT nanocomposites. The resulting organic-inorganic hybrid material, PA NI- MMT has been characterized by various physicochemical techniques. Formation of PANI inside the clay tactoid has been confirmed by X-ray diffraction studies. Infrared spectroscopy studies reveal the presence of physicochemical interaction, probably hydrogen bonding, between clay and polyaniline. One of the main technological applications of conducting polymers, particularly PANI, is in the area of corrosion protection of active metals. PANI-MMT nanocomposites synthesized using the present method is generally used to protect steel surface against corrosion.
\end{abstract}

Keywords Nanocomposites, PANI, Infrared Spectroscopy, Conducting Poly mer, Corrosion

\section{Introduction}

Among the large amount of layered solids such as graphite, layered double hydroxides, transition metal dichalcogenides, metal phosphates and metal phosphonates, clay minerals especially the members of smectite group are the most suitable candidates for synthesis of polymer nanocomposites, because these possess a unique structure and reactivity together with high strength, stiffness and high aspect ratio of each platelet. In particular, montmorillonite $\left[\mathrm{M}(\mathrm{OH})_{2} \cdot \mathrm{nH}_{2} \mathrm{x}(\mathrm{AlMgx}-2 \mathrm{x}) \mathrm{Si}_{4} \mathrm{O} 10(\mathrm{OH})_{2} \cdot \mathrm{nH}_{2} \mathrm{O}\right]$ and hectorite $\left[\mathrm{Mx}(\mathrm{Mg} 3-\mathrm{x} \mathrm{Lix}) \mathrm{Si}_{4} \mathrm{O} 10 \mathrm{H}_{2} \mathrm{O}\right]$, are most widely used in this field. Montmorillonite is a hydrophilic mineral and belongs to the general family of 2:1 (so -called smectite) phyllosilicates composed of stacked layers of aluminum octahedron and silicon tetrahedrons. Substitution of alu minum with magnesium will create an overall negative charge which is compensated by exchangeable metal cations such as $\mathrm{Na}^{+}, \mathrm{K}^{+}, \mathrm{Ca}^{2+}, \mathrm{Mg}^{2+}[1]$. Characteristics of clay minerals which make them important are their particle size and shape, cation exchangeability, adsorption properties and large surface area. The unique structure, low negative charge per

* Corresponding author:

raman_chem@rediffmail.com (A. Venkataraman)

Published online at http://journal.sapub.org/nn

Copyright (C) 2012 Scientific \& Academic Publishing. All Rights Reserved unit cell and weak van der Waals forces between adjacent layers can allow the interlayer space of clay minerals to expand upon the intercalation of organic cations, organic solvent or polymer. Clay minerals speically montmorillonite have widely been employed to synthesize poly mer-clay nanocomposites due to their swelling behaviour, ubiquity and low cost.

With recent advancement in nanotechnology and its potential applications, organic -inorganic nanocomposites have received considerable attention due to the special nature of both components. Conducting polymers including PANI themselves could find their niche in electronics, pharmaceutical, biomedical industries etc. However, there are intrinsic problems with these materials that prevent them from wide commercial applications such as poor processability due to rigid chemical structure and porosity of their coating. Some of these limitations can be overcome by reinforcing the conducting polymers with nanosized filler such as clay particles [2]. The incorporation of clay in conducting polymers may provide characteristics which cannot be attained from pristine conducting polymer such as processability[3]. Among organic-inorganic nanocomposites, PANI-MMT nanocomposites are the most prevalent and interesting due to the special properties as well as wide uses of polyaniline[4], the nature, abundance, low cost of MMT and attractive features such as a large surface area and ion-exchange properties [5]. 
During the last decade, with the developments in frontiers of nanoscience and nanotechnology, considerable attention has been paid to the synthesis and application of functionalized clay/polymer composites [6-8]. The chemistry of functionalized polymers, copolymers and nanoclay composites has attracted greater attention of material scientists and organic chemists in recent times. Clay minerals have been adopted to the field of nanocomposites because of their ultrafine particle size, large surface area and intercalation property in applications such as reinforcement materials with polymers, oil and natural gas separation and extraction, electronic noses and other application devices, particularly, composites of polyaniline and Montomorillonite (MMT)/Bentonite (BT) are potential fillers for the modification of the mechanical and conducting properties of poly mer matrices [8-21].

\section{Materials and Methods}

\section{Synthesis of PANI and its MMT nanocomposites}

The Polyaniline is synthesized via chemical oxidative method. In this method, $0.1 \mathrm{M}$ aniline is dissolved in $0.3 \mathrm{M}$ of sulphuric acid solution. This mixture is kept in ice cold water and $0.1 \mathrm{M}$ ammonium persulphate solution is added, act as oxidizing agent. The polymerization was carried out in cold temperature under magnetic stirring. The resulting PANI was filtered, washed with excess deionized water, dried in vacuu $m$ for 2 days. The final poly mer ground using a mortar and pestle, is used for characterization. In similar method, pani-MMT composites synthesized chemically from aniline free anilinium -MMT (different weights of MMT viz., Pani.0.5, Pani.0.75, Pani. 1.0, and Pani. 1.25 dispersion in $0.3 \mathrm{M}$ sulfuric acid solution. The $0.1 \mathrm{M}$ a mmoniu m persulfate solution was used as oxidizing agent. The polymerization was carried out at room temperature under magnetic stirring. The resulting PANI -MMT was filtered, washed with excess deionized water, dried in vacuum for 4 days. The final PANI -MMT nanocomposites were ground using a mortar and pestle for $\mathrm{X}$-ray diffraction.

\section{Characterization}

The chemical analyses were obtained by using X-ray diffraction studies (Philips goniometer, PW 1730/10, using the $\mathrm{K} \alpha$ radiation of copper). The infrared spectra obtained by using $\mathrm{KBr}$ pellets were recorded with a Perkin Elmer 783 dispersive from 4000 to $400 \mathrm{~cm}-1$. Thermo grav imetric (TG) and differential scanning colorimetry (DSC) experiments were performed using NETZSCHSTA 409 PC. TG and DSC data were obtained at a heating rate of $10^{\circ} \mathrm{C} / \mathrm{min}$ up to $900^{\circ} \mathrm{C}$ under Argon atmosphere. Thermal studies of PANI-composites and pure PANI is analyzed using Linseis STA PT 1600 thermal analyzer at $100 \mathrm{C} / \mathrm{min}$ heating rate under static air atmosphere. The target temperature for the entire sample is maintained up to $900^{\circ} \mathrm{C}$.

\section{Results and Discussions}

FTIR analysis:
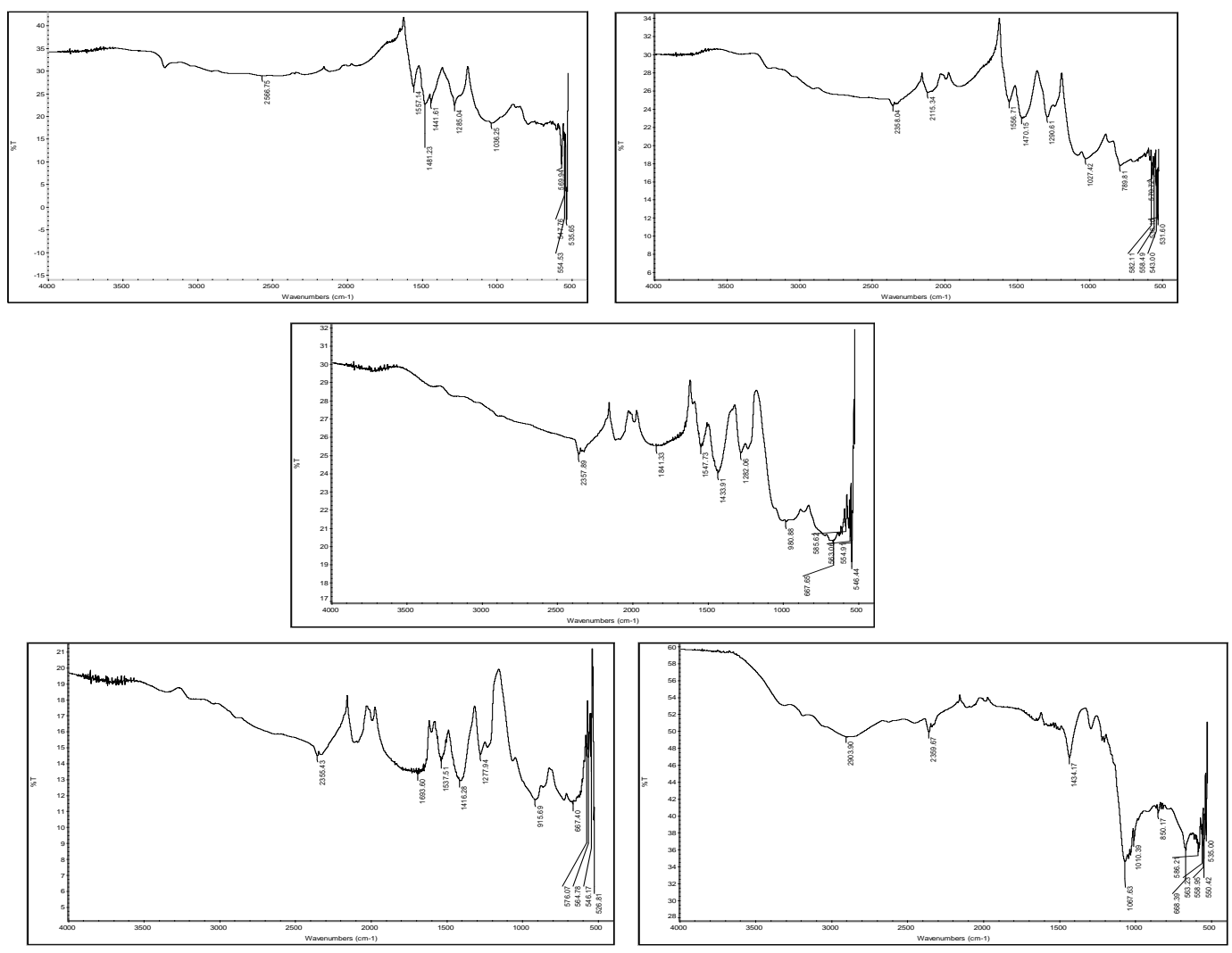

Figure 1. FTIR spectra of PANI_MMT nanocomposites with different concentrations of clay 

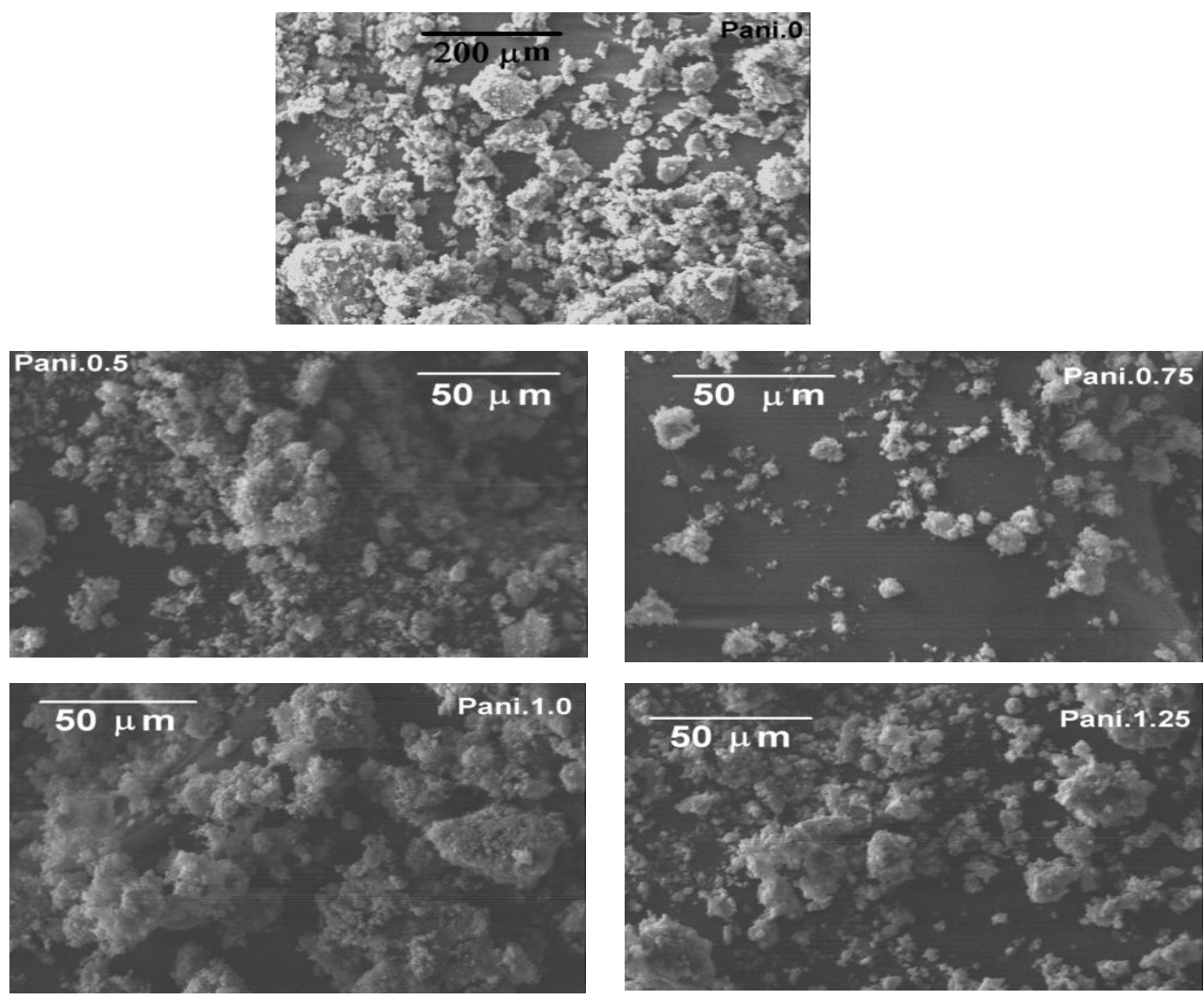

Figure 2. SEM images of Pani-clay at low and high magnifications
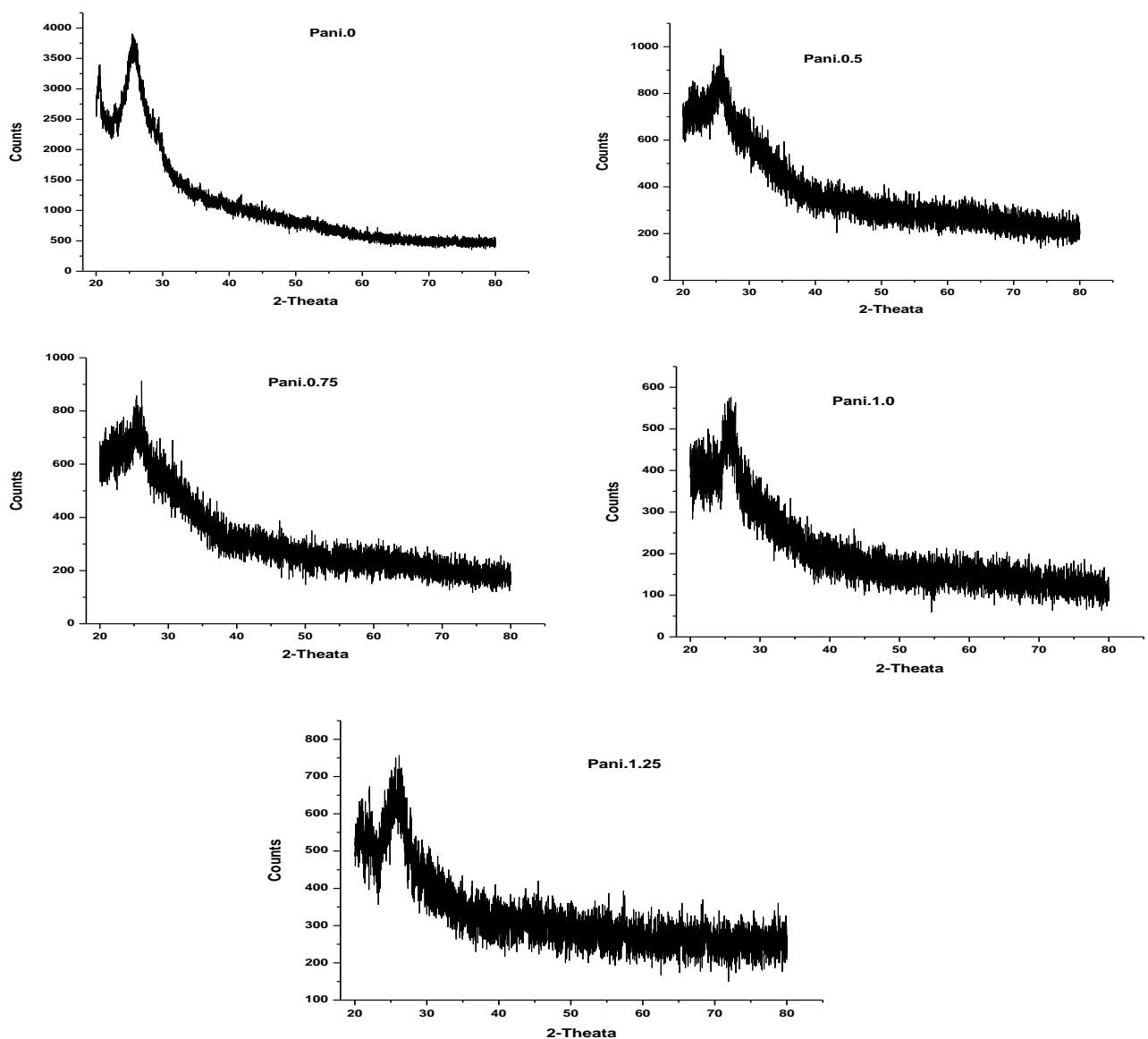

Figure 3. XRD spectra of PANI_MMT nanocomposites with different concentrations of clay 


\begin{tabular}{|c|c|}
\hline FTIR peaks $\mathrm{cm}^{-1}$ & Assigned Functional Groups \\
\hline $800-900$ & Out of plane $\mathrm{C}-\mathrm{H}$ bond \\
\hline 1038 & Si-O stretching (Clay) \\
\hline $1285-1300$ & $\begin{array}{l}\text { C-N st retching of the secondary aromat ic } \\
\text { amine }\end{array}$ \\
\hline $1400-1480$ & Benzenoid rings. \\
\hline $1500-1567$ & Quinoid rings. \\
\hline
\end{tabular}

FTIR analysis: The spectrum showed peaks at $1290 \mathrm{~cm}^{-1}$, $1441 \mathrm{c} \mathrm{m}^{-1}$, which are the characteristic peaks of polyaniline. The relative intensity of the 1557 and $1481 \mathrm{~cm}^{-1}$ indicates the oxidation state of the material. For Pani, the peak area ratio was 1.0 the polymer is in the emeraldine salt. The peaks observed at $500-600 \mathrm{~cm}^{-1}, 1067 \mathrm{c} \mathrm{m}^{-1}$ are due to the presence of clay in the composite. The peak assignments are listed in the table[22- 25]. The spectrum showed characteristic peaks of polyaniline and clay at 1067 and $1430 \mathrm{~cm}^{-1}$, the IR spectrum for the different composites is shown in the fig ure 1. It was difficult to detect the presence of polyaniline and clay in this system using IR spectrum. This could be due to the masking effect of polyaniline on the powder. As this was a filtered system, very fine particles were present in the system.
It is believed that the polyanilne matrix surrounded these particles, making it difficult to characterize them.

Figure 2 shows SEM micrographs images of Pani-clay composites with different amount of clay in the composites. Scanning electron micrograph (SEM) revealed some interesting morphological differences between the pure bentonite clay and Pani-clay composites. The surface of pure clay was flaky texture reflecting its layered structure[26] as shown in figure. Pani has a rod like network texture and Pani Clay composite has flower petals like appearance. It can be clearly seen in micrographs of all clay composites that the textures of both pani-clay are retained in the composites which are of different grain sizes. The micrographs of pani-clay $1.25 \%$ composites exhibit more ordered and dense structure (smaller sizes with high density of granules per unit area) comparing to pani-clay composite comparing to pani-clay $1.0 \%$ clay (bigger sizes with less density per unit area). It shows that the increase in clay percentage in the preparation solution will increase the compactness.
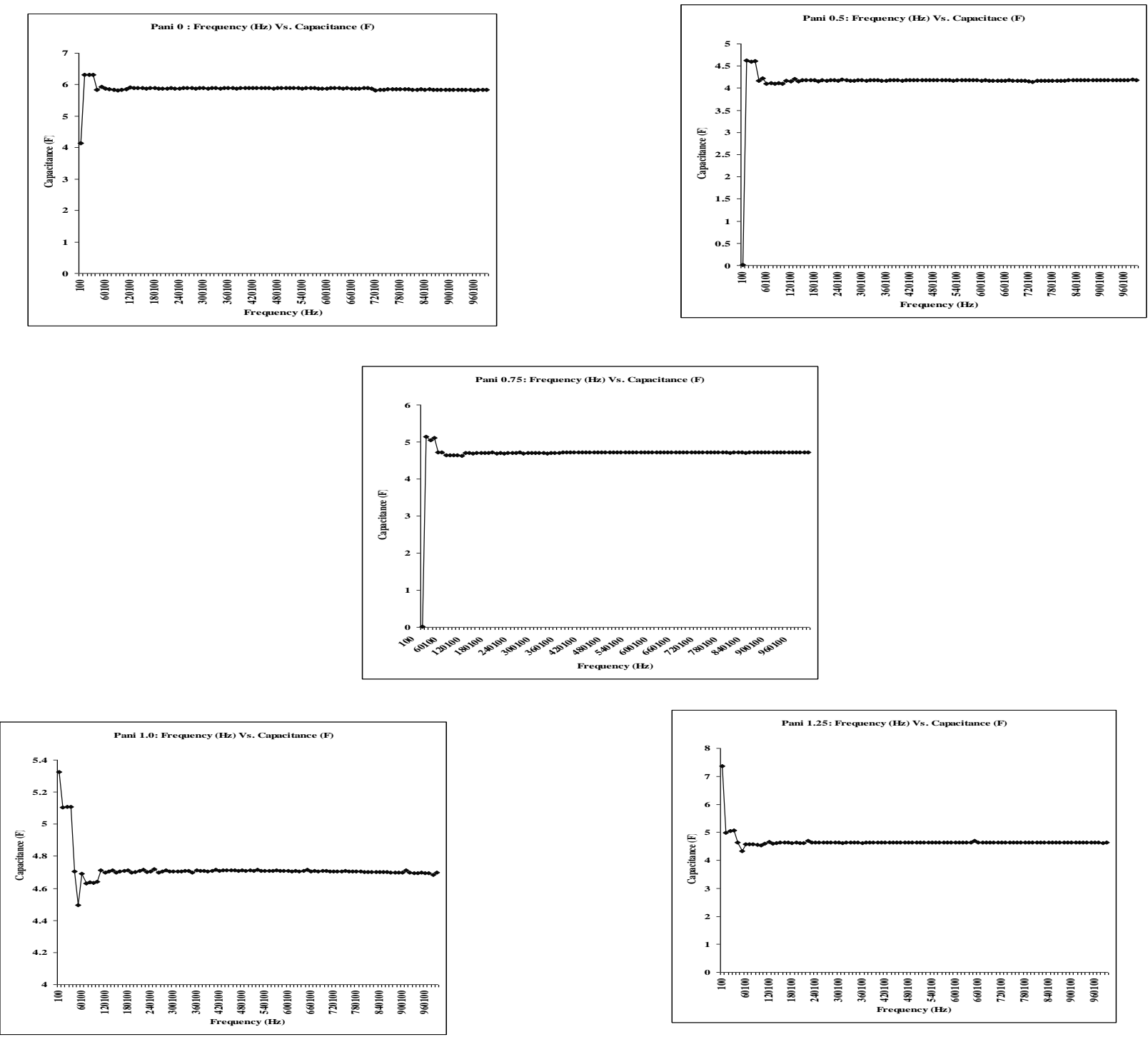

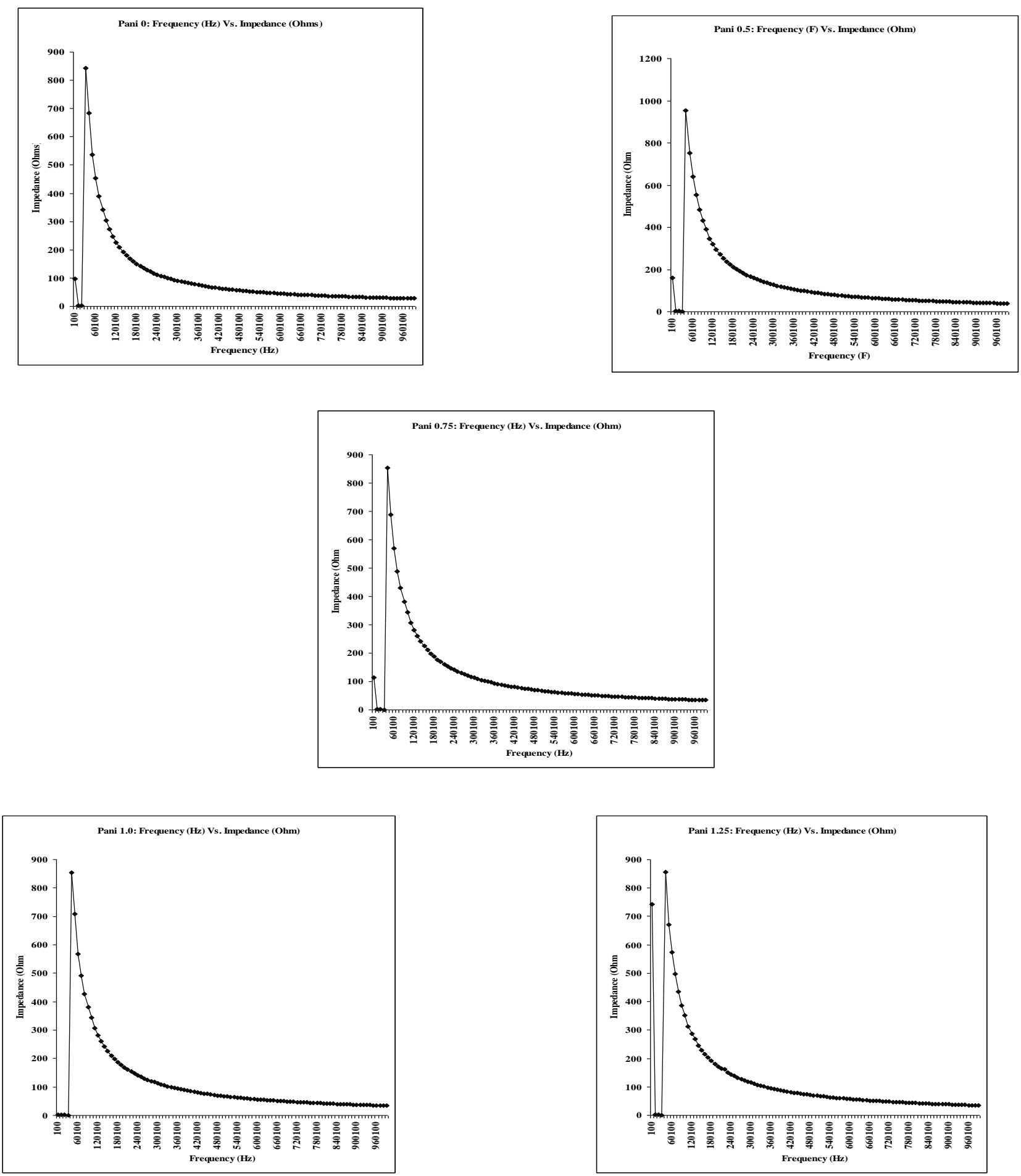

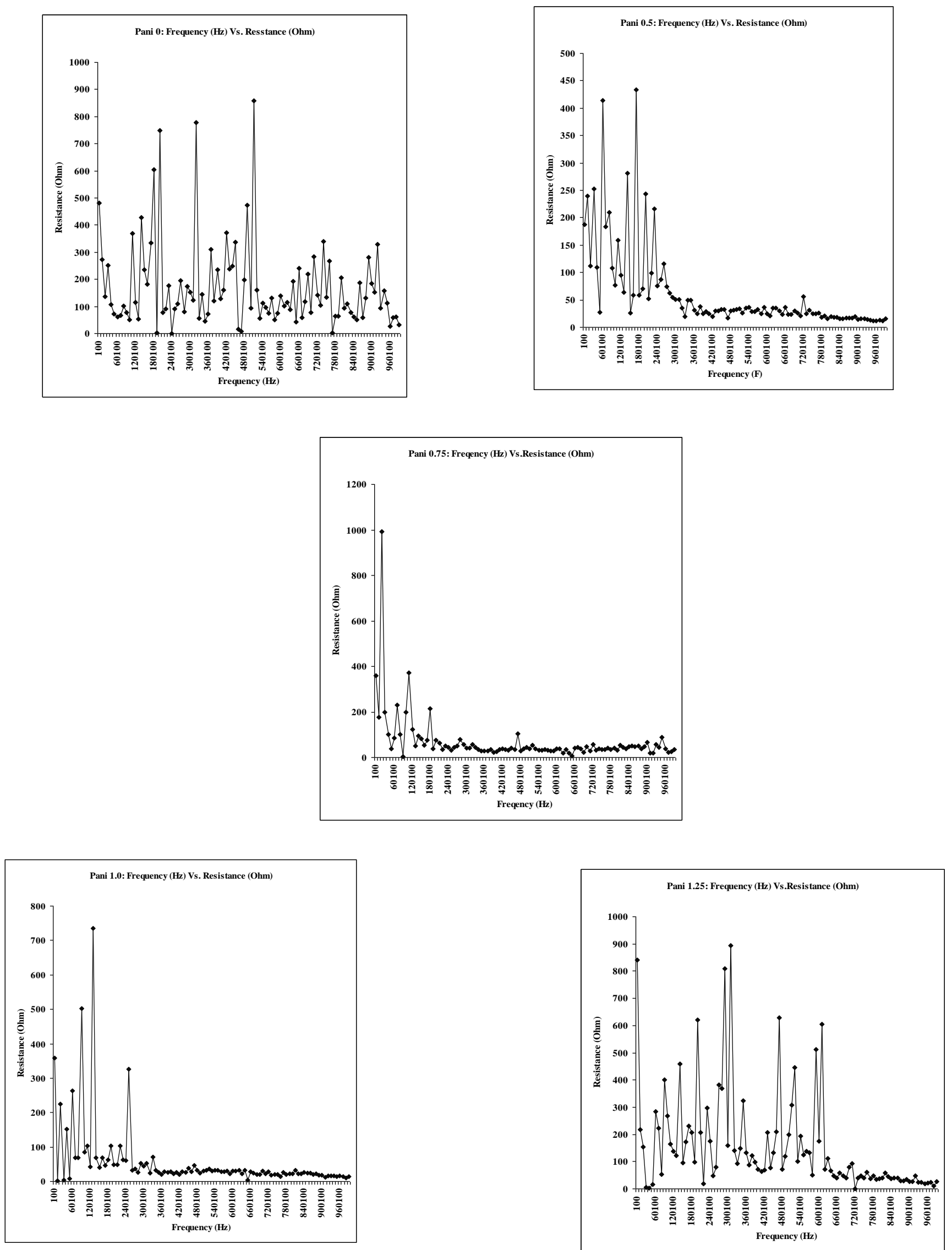

Figure 4. Electrical parameters versus frequency 

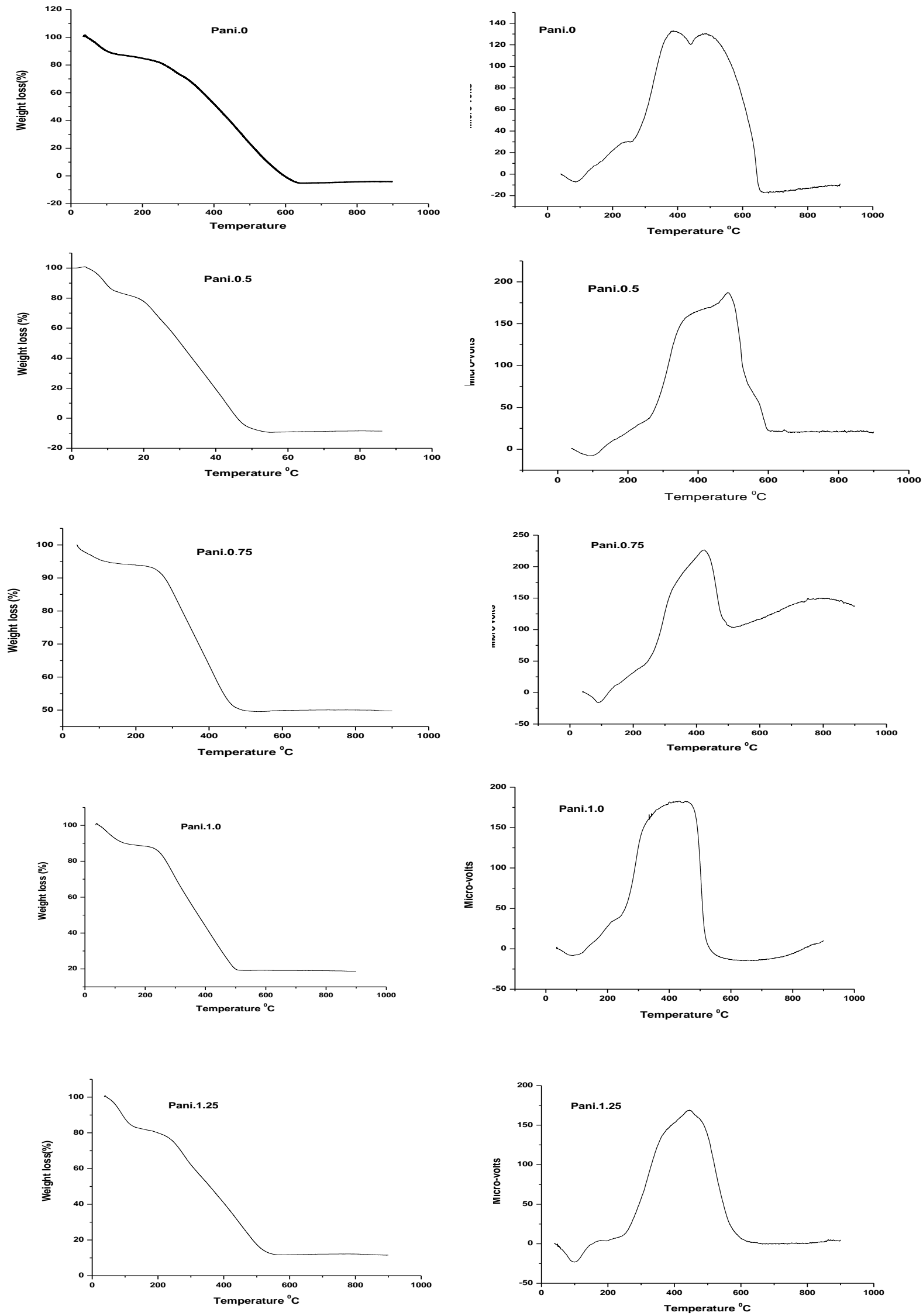

Figure 5. TGA/DSCtraces of pani-clay composites 
It should also be noted here that most of the pani-clay composites chains are intercalated into the interlayer spacings of clay based on the XRD data shown in figure 3. As a result, this SEM data strongly support the fact that the pani chains (i.e. free pani-clay domains) play an important role in the electrical conductivity of the composites. It is evident that the improvement in the conductivity of the pani-clay composite could be attributed to more ordered and dense structure enhancing inter-chain electron hopping [26].

Insertion of the clay into the pani was also examined by $\mathrm{XRD}$, which confirmed that the pani chain was aligned with the clay. Figure 3 shows X-ray diffraction pattern for Pure Pani, Pani.0.5, Pani.0.75, Pani.1.0 and Pani.1.25. All the spectra show amorphous structure due to the absence of sharp peaks. The broad maxima in the $2 \theta$ were obtained in the range of 250 for all the samples (including Pure Pani). which suggests the structure of pure pani to be amorphous.[27].

\section{Electrical Parameters:}

Figure 4shows the various electrical parameters versus frequency were plotted and the results were correlated with pure poly mer (pani) and poly mer clay co mposites for various compositions. These results show noticeable change in electrical properties of the composites as compared with the pure polymer[28].

\section{Thermal analysis:}

Thermal stability of polyaniline/caly composites of different composition have been analyzed and compared with that of pure pani. Figure 5shows the thermal traces of Pani-clay nanocomposites and pure pani. The initial weight loss of $5-10 \%$ (up to $180^{\circ} \mathrm{C}$ ) is due to the loss of physically adsorbed water. From the TGA result it is observed that weight loss of Pani-clay composite is less compared to pure pani. This is clear indication of thermal stability of pani-clay composites [29-30]. It is observed that the shift in the DSC thermogram and peak area of polymer-clay composites is less compared to pure Pani[31]. From the present result it can be predicted that the thermal stability of pani-clay composites is enhanced due to the attractive coulomb interaction between the positive group of Pani Layer and negatively charged surface of the clay layer.

\section{Conclusions}

Poly mer-clay based composites of pani were successfully obtained by polymerizing polyaniline in the presence of ammonium persulphate-impregnated clay by chemical oxidative method. From these XRD patterns and the SEM photographs it is observed. That there is possible intercalation of PANI in clay. This justified the objective that this clay can be used for synthesizing PANI clay composite. The intercalation of Pani- Bentonite. The shift in IR peaks of the Pani-clay samples suggest interaction between the Pani-clay composites. The morphological study from the SEM analysis shows the compact morphology with the increase in clay. From the TGA/DSC results, we observe the thermal stability of the nanocomposites of Pani-clay is relatively enhanced through the intercaltion. Frequency versus various electrical parameters graph show, enhanced shifts in values of electrical parameters, reflecting possible changes in property values with relative percentage of clay.

\section{ACKNOWLEDGEMENTS}

Financial support from the DAE-BRNS (No.2009/34/14/ BRNS), UGC Innovative programme (No. F.14-54/2007 Innov/assist) and VGST, Bangalore (Proposal ref. no D38/7) are acknowledged.

\section{REFERENCES}

[1] Q. H. Zeng, D. Z. Wang, A. B. Yu, and G.Q. Lu, "Synthesis of polymer-montmorillonite nanocomposites by in situ intercalative polymerization" Nanotechnology, vol. 13,pp. 549-553, Aug.2002.

[2] B. Feng, Y. Su, J. Song, and K. Kong, "Electropolymerization of poly aniline/montmorillonite nanocomposite " J. Mater. Sci. Lett., vol. 20, pp. 293-294, 2001.

[3] Y. Zhu, Synthesis, characterization and corrosion performance of poly aniline montmorillonite clay nanocomposites, $\mathrm{PhD}$ thesis, 2003.

[4] D.B.Mahesh, S.Basavaraja, D.S. Balaji, V.Shivkumar, L.Arunkumar, and A.Venkataraman, "Preparation and characterization of Pani and Pani-Ag nanocomposites via interfacial polymerization", Polymer Composites Vol. 30, Issue 11, pp. 1668-1677, November 2009.

[5] S. Yoshimoto, F. Ohashi, Y. Ohnihi, and T. Nonami, "Synthesis of Poly aniline - montmorilonite nanocompposites by the mechanochemical intercalation method", Synth. Met, vol. 145, pp. 265-270 September,2004.

[6] S. Yoshimoto, F. Ohashi, and T. Kameyama, "Simple Preparation of Sulfate Anion-Doped Polyaniline-Clay Nanocomposites by an Environmentally Friendly Mechanochemical Synthesis Route", Macromolecular Rapid Communications. Volume 25, Issue 19, pages 1687-1691, October, 2004.

[7] N. Hasegawa, H. Okamoto, M. Kawasumi, M. Kato, A. Tsukigase, and A. "Usuki. Polyolefin-clay hybrids based on modifiedpolyolefins and organoclay". Macromol. Mater. Engng., Vol. 280/281,pp. 76-79,2000.

[8] M. Alexandre, and P. Dubois, "Polymer-layered silicate nanocomposites: preparation, properties and uses of a new class of materials", Mater. Sci. Eng., vol.28,pp.1-63, March 2000.

[9] D. Garcia-Lopez, O. Picazo, J.C. Merino, and J.M. Pastor, "Polypropylene - clay nanocomposites: effect of compatibilizing agents on clay dispersion", European Polymer Journal, vol.39 pp. 945-950, 2002.

[10] T. Agag, and T.Takeichi,."Polybenzoxazine-Montmorillonite Hybrid Nanocomposites Synthesis and Characterization", 
Poly mer, vol. 41(19), pp. 7083-7090, 2000.

[11] M.H. Al-Saleh, and U. Sundararaj, "Processing -microstructure-property relationship in conductive polymer nanocomposites", Poly mer, vol. 51, 2740-2747, 2010.

[12] S.H. Hong, B.H. Kim, J. Joo, J.W. Kim, and H.J. Choi, Polypyrrole-montmorillonite nanocomposites synthesized by emulsion polymerization", Curr. Appl. Phys.vol.1, pp.447-450, Dec.2001.

[13] M. Omastova, M. mrave'a' kova, J. Piontek, and I. Choda'k. In proceeding of the conference Nanocomposites, San Francisco, USA, 2003.

[14] H. Enomoto, and M.M. Lerner, "Synthesis of polymer/1T-TaS2 layered nanocomposites", Mater. Res. Bull., vol.37, pp. 1499-1507, July 2002.

[15] M.H. Yeh, W.S. Hwang and Y.C. Chang, "Preparation and Mechanical Properties of Polychloroprene-Montmorillonite Composites", Jpn. J. Appl. Phys. Vol.44 pp. 6847-6854, Sept.2005.

[16] P.Kiliaris, and C.D. Papaspyrides, "Poly mer/layered silicate (clay) nanocomposites: An overview of flame retardancy", Prog. Polym. Sci., vol. 35, 902-958, 2010.

[17] Q.H. Zeng, A.B. Yu, G. Q. Lu (Max), and D.R. Paul, "Clay-Based Polymer Nanocomposites: Research and Commercial Development", Journal of Nanoscience and Nanotechnology, Vol. 5, No. 10, pp. 1574-1592,October 2005.

[18] S.S. Ray, and M. Okamoto, "Polymer/layered silicate nanocomposites: a review from preparation to processing" Prog. Polym. Sci.. vol.28, pp. 1539-164, Aug. 2003.

[19] S. Letay ef, P. Aranda, and E. Ruiz-Hitzky. "Influence of iron in the formation of conductive polypy rrole-clay nanocomposites”, Appl. Clay Sci., vol.28, pp. 183-198, 2005.

[20] G.M. do Nascimento, V.R.L. Constantino, R. Landers, and M.L.A. Temperini, "Aniline Polymerization into Montmorillonite Clay: A Spectroscopic Investigation of the Intercalated Conducting Polymer", Macromolecules, vol.37, pp. 9373-9385, Nov. 2004.

[21] D. Lee, K. Char, S.W. Lee, and Y.W. Park, "Structural changes of poly aniline/montmorillonite nanocomposites and their effects on physical properties", J. Mater. Chem., vol. 13, pp. 2942-2947, 2003.

[22] N. Ballav, and M. Biswas, "A conducting nano composite via intercalative polymerisation of thiophrene in montmorillonite clay", Synth. Met., Vol.142, 309-315, April 2004.

[23] Bedre, M.D.; Salimath, B.; Sawle, B.; Lagashetty, A.; Venkataraman, A. Polymer Compos 30, 2009, 1668.

[24] Swaruparani, H.; Basavaraja, S.; Basavaraja, C.; Huh, D. S.; Venkataraman, A. J App Polym Sci doi 10.1002/app.31745.

[25] R.L. Frost, and A.M .Vassallo, "The dehydroxylation of the kaolinite clay minerals using infrared emission spectroscopy", Clays and Clay Minerals, Vol. 44, No. 5, pp.635-651, 1996.

[26] M. Darder, M. Colilla, and E. Ruiz-Hitzky, "Biopolymer-Clay Nanocomposites Based on Chitosan Intercalated in Montmorillonite",Chem. Mater., vol.15 (20), pp 3774-3780, Sept.2003.

[27] A. Kassim, M. Sagadavan, F. Adzmi, H.N. and M. Mahmud Ekramul, "Conducting polymer/clay composites: Preparation and characterization”, Materials Science (Medziagotyra), vol. 10/3, pp. 255-258, 2004.

[28] Abdul Shakoor, Tasneem Zahra Rizvi and Ahmad Nawaz, "Raman spectroscopy and AC conductivity of polynailine montmorillonite (PANI-MMT) nanocomposites", J. Mat. Sci. Mater. Electronics, vol. 22 No. 8, 1076-1080, 2011.

[29] S.S. Ray, and M. Bousima, "Biodegradable polymers and their layered silicate nanocomposites: in greening the $21 \mathrm{st}$ century materials world", Prog. Mater. Sci. Vol. 50, pp. 962-1079, 2005.

[30] O. Becker, R.J. Varley, and G.P. Simon,'Thermal stability and water uptake of high perfmormance epoxy layered silicate nanocomposites". Euro. Polym. J., Vol. 40, pp.187-195, 2004.

[31] S.S. Deng and L. Guang, "Preparation and Characterization of Poly aniline/Montmorillonite Composite by Situ Emulsion Polymerization", J. Advan. Mater. Research, vol. 476-478, pp. 809-813, 2012. 